\title{
Porque a distância histórica não é um problema*
}

\author{
Why Historical Distance is not a Problem
}

\author{
Mark Bevir ${ }^{1}$ \\ Professor \\ University of California - Berkeley \\ 900 University Avenue \\ Riverside, CA 92521 \\ United States of America
}

\section{Resumo}

Este artigo argumenta que as preocupações acerca da distância histórica surgiram junto ao historicismo moderno, e que elas desapareceram com o pós-fundacionismo. O historicismo desenvolvimentista do século XIX recorreu a princípios narrativos para estabelecer a continuidade entre passado e presente, e para guiar as seleções entre os fatos. No século XX, os historicistas modernos rejeitaram tais princípios, levantando assim o espectro da distância histórica; ou seja, os efeitos distorcidos do presente em relação ao passado, o abismo entre os fatos e a narração. O problema moderno era: como os historiadores podem evitar o anacronismo e desenvolver representações precisas do passado? Ao invés de utilizar princípios narrativos para selecionar fatos, os historicistas modernos apelaram aos fatos atomizados para validar narrativas. Todavia, no final do século XX, os pós-modernos (Frank Ankersmit e Hayden White) argumentaram que não havia uma maneira de estreitar a distância entre fatos e narrativas. O problema pós-moderno tornou-se o seguinte: como os historiadores deveriam conceber suas escritas, dada a inelutável distância entre fatos e narrativas? Hoje, o pós-fundacionismo descarta as preocupações tanto modernas quanto pós-modernas com a distância histórica; isso implica que todos os conceitos (não somente históricos) fundem fato e teoria; e dissolve questões de relativismo conceitual, significado textual e reencenação.

\section{Palavras-chave}

Anacronismo; Modernismo; Pós-modernismo.

\begin{abstract}
This essay argues that concerns about historical distance arose along with modernist historicism and disappeared with postfoundationalism. The developmental historicism of the $19^{\text {th }}$ century appealed to narrative principles in order to establish the continuity between past and present, and to guide selections among facts. In the $20^{\text {th }}$ century, modernist historicists rejected such principles, thereby raising the specter of historical distance; that is, the distorting effects of the present in accounts of the past, the chasm between facts and narrative. The modernist problem was: how can historians avoid anachronism and develop accurate representations of the past? Instead of using narrative principles to select facts, modern historicists appealed to atomized facts to validate narratives. However, in the late $20^{\text {th }}$ century, postmodernists (Frank Ankersmit and Hayden White) argued that there was no way to close the distance between facts and narratives. The postmodern problem became then: how should historians conceive of their writing, given the ineluctable distance between facts and narratives? Today, postfoundationalism casts off both modernist and postmodernist concerns with historical distance; this means that all concepts (not only historical concepts) fuse fact and theory, and also dissolves issues of conceptual relativism, textual meaning, and reenactment.
\end{abstract}

\section{Keywords}

Anachronism; Modernism; Postmodernism.

Recebido em: 16/8/2014

Autor convidado

\footnotetext{
${ }^{*}$ Do original: BEVIR, Mark. Why Historical Distance is not a Problem. History and Theory, vol. 50, n. 4, p. 24-37, 2011. Tradução de Thiago Livon e Sérgio Campos Gonçalves.

1 Professor no Departamento de Ciência Política da Universidade da Califórnia - Berkeley. É autor de The Logic of the History of Ideas (1999), New Labour: A Critique (2005), Key Concepts of Governance (2009), e Democratic Governance (2010); e coautor, juntamente com R.A.W. Rhodes, dos livros Interpreting British Governance (2003), Governance Stories (2006) e The State as Cultural Practice (2010).
} 


\section{Porque a distância histórica não é um problema}

A distância histórica - a diferença entre o passado e presente ou entre fato e narrativa - estava entre os assuntos mais amplamente discutidos em teoria histórica durante o século XX. Ainda assim, a distância histórica não é um problema perene, ela não surge inevitavelmente para aqueles que possuem uma sensibilidade historicista e escrevem histórias. Pelo contrário, irei argumentar que a questão da distância histórica se dissemina somente com as teorias históricas modernas do início e do meio do século XX, e embora tenha persistido através das teorias históricas pós-modernas do final do século $X X$, ela desaparece uma vez que consideramos totalmente as implicações do pós-fundacionismo.

Começo este artigo contextualizando as preocupações acerca da distância histórica. As teorias do desenvolvimento histórico do século XIX recorreram a princípios teleológicos e materiais para garantir a continuidade entre passado e presente e para concatenar fatos e narrativa. No começo do século XX, no entanto, surgiram novas formas modernas do saber que refutaram esses princípios. Por "modernismo" não pretendo evocar um contraste com "medieval" ou com "os primórdios do moderno". Em vez disso, o modernismo se refere aqui, preferencialmente, à troca cultural no final do século XIX e início do século XX que promoveu abordagens mais fragmentadas e formais à arte e ao conhecimento. O modernismo teve uma orientação analítica e atomística. Isso minou a confiança na continuidade do passado e presente. Dessa maneira,

12 os historiadores confrontaram preocupações substanciais sobre como, dentro do presente, eles poderiam desenvolver conceitos e narrativas capazes de superar a distância entre seu mundo e o passado. Os modernos associaram a teoria histórica com a discussão sobre como evitar anacronismos e garantir que suas narrativas estejam adequadas aos fatos. Eles apelaram para métodos rigorosos para garantir fatos atomizados, que, por sua vez, poderiam justificar as narrativas. Em contrapartida, pós-modernos como Frank Ankersmit e Hayden White argumentaram que não haveria um caminho possível de superar as distâncias entre passado e presente, como também entre os fatos históricos e as narrativas dos historiadores. Eles redefiniram a teoria histórica como o estudo dos modos por meio dos quais a escrita histórica se baseia em instrumentos literários e estéticos para transformar fatos e descrições em narrativas e representações.

Meu objetivo, no entanto, não é apenas contextualizar as preocupações modernas e pós-modernas em relação à distância histórica, mas também dissipálas. A chave para dissipar os problemas da distância histórica é reconhecer os temas modernos remanescentes nos relatos de fatos e descrições de Ankersmit e White. Esses pós-modernos ainda trataram de fatos e descrições enquanto conhecimento atomístico e declarações que possuem conteúdo de significado fora dos contextos teóricos e das narrativas. Em contraste, o pós-fundacionismo implica que todos os fatos são carregados de teoria, pois nenhuma proposição poderia ser referenciada fora do contexto de uma ampla rede de crenças. $O$ pós-fundacionismo, assim, dissipa ambas as ideias pós-modernas e modernas 
da distância histórica. Ele sugere que os historiadores não podem acessar o passado e certificar os fatos a não ser dentro do contexto de seus conceitos e teorias. O passado apenas aparece nas nossas crenças atuais, ele nunca é dado à distância.

Talvez possa ser que exista um tipo diferente de distância dentro das nossas crenças presentes e os termos que aplicamos para o passado e para aqueles que aplicamos aos presentes, e talvez essa distância possa provocar preocupações sobre o relativismo conceitual, significado textual e re-encenação. Concluo o artigo, no entanto, sugerindo que o pós-fundacionismo também dissipa - ou pelo menos dilui - essas preocupações.

\section{Os problemas da distância histórica}

As preocupações sobre a distância histórica disseminaram-se em um contexto particular. No século XIX, teorias românticas (ou, para ser mais preciso, desenvolvimentistas) sempre enfatizaram a natureza orgânica, significativa e até espiritual da história concebida como uma unidade progressiva. Historicistas desenvolvimentistas não eram hostis aos fatos, ao rigor, ou à objetividade. ${ }^{2}$ Eles acreditavam que as narrativas objetivas requeriam uma compilação rigorosa de fatos imparciais, sistemáticos e minuciosos. Ainda assim, eles coletaram e esmiuçaram os fatos no contexto das narrativas desenvolvimentistas. Esse historicismo desenvolvimentista emergiu na gama de variados modos de pensamento, incluindo a teorização evolucionária, as histórias conjunturais Whig derivadas do Iluminismo escocês, do romantismo e do idealismo associados, sobretudo, a G.W. Hegel, e a uma ênfase organicista mais ampla na habilidade dos seres humanos em estabelecer instituições sociais agindo em acordo com o propósito, o pensamento e a imaginação (BURROW 1966; 1981). As narrativas desenvolvimentistas atraíram ambos os lados na disputa entre positivistas e idealistas. Os positivistas seguiram Augusto Comte, J. S. Mill, e Leopold von Ranke ao promover métodos rigorosos, mas eles viram a teoria da evolução como o pináculo da ciência e, assim, como um contexto teórico adequado para se situar os resultados empíricos (BEVIR 2002; CAPALDI 2004; ROSS 1990). Os idealistas definiram o absoluto como a perfeição espiritual, mas se sustentaram no Hegelianismo e no organicismo social para delinear contextos desenvolvimentistas no qual o absoluto aflorou (OTTER 1996).

Os historicistas desenvolvimentistas contavam narrativas de continuidade e progresso baseados em princípios teleológicos e materiais, como o ego, a nação, a razão e o espírito. As questões sobre a distância histórica raramente surgiam. De início, os historicistas desenvolvimentistas se basearam em princípios teleológicos e materiais para postular a unidade da história. Os princípios de nação, da razão, e do espírito prenderam o passado e o presente juntos em um

\footnotetext{
${ }^{2}$ Ao longo do texto, utilizo o termo historicismo para me referir às tentativas de explicar a atividade humana diacronicamente ao invés de uma maneira mais formal e estrutural. Embora este conceito de historicismo seja disseminado, meu objetivo é contar uma narrativa histórica do historicismo focando no conhecimento anglófono. Esse objetivo pode explicar como e porque minhas subcategorias - desenvolvimento, moderno, pós-moderno - se sobrepõem e, contudo, se diferem daquelas associadas às explorações do historicismo expressas em termos de um impulso religioso ou de uma matriz disciplinar.
} 
todo orgânico. Diferentes eras históricas foram unidas por uma comunhão da experiência. Além do mais, os historicistas desenvolvimentistas normalmente compreenderam o passado ao localizá-lo em relação a seus conceitos amplos de nação, razão e espírito. Eles se fundamentaram em princípios teleológicos e substanciais para selecionar fatos e dar sentido a suas narrativas. Eles se concentraram em mudanças incrementais nas ideias e instituições associadas com o triunfo desses princípios. Até mesmo quando eles apontaram para as ameaças desses princípios, ainda conceberam o progresso como algo construído na ordem das coisas.

A perda de fé no progresso e na razão começou no final do século XIX e veio a se tornar disseminado em seguida à Primeira Guerra. Imagens e ideais de progresso continuaram a aparecer depois da Grande Guerra, mas o progresso foi crescentemente retratado como uma vitória contingente da atividade humana, não como uma característica inelutável da história (KLOPPENBERG 1986). As pessoas frequentemente argumentaram que o progresso dependeu da promoção de novas ciências para resolver problemas sociais. A Primeira Guerra Mundial encorajou o interesse para as novas ciências ainda que elas tenham erodido a fé no desenvolvimento histórico. As novas ciências caracteristicamente se apoiaram no empirismo moderno (ADCOCK; BEVIR; STIMSON 2007; ROSS 1991). Elas romperam a continuidade com as antigas narrativas desenvolvimentistas, dividindo o mundo em unidades discretas e descontínuas, e construindo o sentido dessas unidades por meio de regras matemáticas e esquemas analíticos.

14 Nas ciências sociais, o empirismo moderno inspirou a ascensão das correlações a-históricas, dos modelos formais e dos sistemas funcionais como modos alternativos de explicação para as antigas narrativas históricas.

É importante enfatizar que a troca do historicismo desenvolvimentista pelo empirismo moderno foi um dos modelos de explicação - uma mudança do pensamento desenvolvimentista para a teorização formal. Muitos historiadores do século XIX foram fervorosos investigadores de fatos que lideraram a propagação de métodos rigorosos, e alguns deles até compreendiam-se como concentrados unicamente em certificar os fatos, sugerindo que o tempo para narrativas que ainda não havia chegado; embora em geral eles ainda compreendiam e certificavam esses fatos por meio de apelos explícitos e implícitos a um conjunto existente ou projetado de princípios e a uma narrativa desenvolvimentista ou teleológica. Da mesma forma, alguns modernos do século XX concentraram-se em esquemas especulativos em vez de métodos ou fatos; mas seus esquemas eram modelos e correlações formais e versões sincrônicas de sistemas e estruturas.

Os historiadores eram menos prováveis de rejeitar explanações históricas que os cientistas sociais, mas eles se afastaram do pensamento desenvolvimentista. Os historiadores modernos adotaram uma abordagem mais atomística dos fatos, na ausência de princípios substanciais e teleológicos. Eles então tentaram encontrar uma maneira de certificar os fatos fora do contexto de narrativas mais amplas. A distância histórica parecia ser tanto um benefício quanto um obstáculo na obtenção dos fatos. Por um lado, alguns historiadores modernos se basearam no legado empirista de Comte, Mill e Ranke para argumentar 
que a passagem do tempo, na verdade, facilita uma perspectiva abrangente e imparcial (NOVICK 1988). Eles enfatizaram que os historiadores tipicamente têm que esperar que papéis e arquivos oficiais se tornem públicos antes que possam ter acesso completo a todos os fatos relevantes. Eles também sugeriram que historiadores frequentemente requerem uma distância emocional de seu material para que sejam objetivos. Por outro lado, no entanto, os historiadores modernos tinham que estar certos de que o tempo não esconde ou distorce os fatos. Eles então tentaram criar métodos que os capacitariam em recuperar fatos perdidos e abandonados. Eles até sugeriram que métodos rigorosos poderiam assegurar a validade e veracidade dos fatos. Assim, a teoria histórica moderna consistiu, sobretudo, na tentativa de usar métodos rigorosos para estabilizar fatos atomizados os quais, por sua vez, poderiam determinar conclusivamente a verdade ou a falsidade das narrativas (BENTLEY 2005).

Isso se deu porque os modernos tinham uma visão mais atomística dos fatos que o problema da distância histórica disseminou. Os modernos rejeitaram os princípios materiais e teleológicos com os quais os historiadores desenvolvimentistas tinham criado a continuidade entre passado e presente e selecionado os fatos para inclusão em suas narrativas. Sem dúvidas, a consciência histórica mais ou menos por definição envolve algum tipo de distinção entre passado e presente. Igualmente, todavia, uma distinção entre passado e presente não precisa implicar quaisquer preocupações sobre as dificuldades epistêmicas em conhecer o passado, dado que ninguém tentaria realizá-la de uma perspectiva do presente; isso poderia envolver algumas preocupações, mas não há necessidade. Sendo assim, os historiadores desenvolvimentistas acreditaram em princípios materiais e teleológicos que garantiam a habilidade de compreender o passado em termos condicionados pelo presente. Foi apenas quando os modernos rejeitaram esses princípios que perderam esta garantia de uma ponte que liga o presente de volta ao passado. Desse modo, os modernos transformaram a consciência da distinção entre passado e presente em problemas de distância histórica. Perguntaram como - na ausência das continuidades então certificadas por princípios desenvolvimentistas - os historiadores puderam compreender outros tempos senão o deles? Em princípio, quando os modernos rejeitaram os princípios que ligavam o passado e o presente, eles deram um novo estímulo para a questão de como os historiadores poderiam saber que seus conceitos não eram anacrônicos. Além disso, quando os modernos rejeitaram os princípios que regem as seleções dos fatos para a inclusão em narrativas, eles levantaram a questão de como as narrativas dos historiadores eram relacionadas aos fatos.

Em geral, os modernos responderam ao problema da distância histórica recorrendo a rigorosos métodos empíricos na tentativa de certificar os fatos atomizados que, por sua vez, certificavam as narrativas. Peter Laslett fornece apenas um exemplo. Laslett apresentou uma coleção editada, intitulada Philosophy, Politics, and Society, com um manifesto estridentemente moderno (LASLETT 1956). Ele evocou um positivismo que equacionou o conhecimento com a ciência empírica e limitou a teoria à rigorosa análise do uso da linguagem, conforme exemplificado pelo trabalho de Gilbert Ryle e T.D. Weldon. A edição de 
Laslett dos Two Treatises de John Locke forneceu um exemplo triunfante da nova história moderna. Ele abordou os Two Treatises utilizando as fontes e técnicas consideradas pelos historiadores modernos. Ele se baseou em documentos de arquivos primários - a biblioteca de Locke, lista dos livros que Locke possuía, cópias manuscritas dos Two Treatises, o diário e cartas pessoais de Locke. Estas fontes forneceram-Ihe fatos sobre os quais ele baseou sua interpretação histórica. O reconhecimento das datas em que Locke lia os livros sugeriu que Locke havia escrito passagens referindo-se a esses livros após essas datas. O trabalho de Laslett revolucionou a visão dos historiadores sobre Locke. Ele mostrou que Locke tinha escrito a maior parte do Second Treatise em 167980. Os Two Treatises, possivelmente, não poderiam ter sido escritos como uma defesa da Revolução Gloriosa. Eles eram "um Tratado de Exclusão" clamando por uma revolução (LASLETT 1960, p. 61).

Os historiadores modernos queriam utilizar fatos seguros e atomizados para defender a validade das narrativas. Eles enfrentaram a questão de como superar a distância histórica para ter a certeza dos fatos. Como poderiam evitar os efeitos discursivos de seu presente atual? Como poderiam evitar o anacronismo e descobrir os fatos? Em geral, os historicistas modernos recorreram a métodos rigorosos. Quentin Skinner - que fez "para Hobbes o que Laslett havia feito para Locke" - fornece um exemplo (SKINNER 2002, p. 42). Skinner defendeu o contextualismo como um método moderno que estabeleceria fatos e decidiria a validade das narrativas. Ele sempre descreveu seu método como um "necessário e talvez até suficiente" - ou mais coloquialmente um "essencial" - requisito para um entendimento adequado de um texto histórico. Skinner argumentou que, como a expressão e recepção da força ilocucionária requer convenções compartilhadas, os historiadores devem estudar contextos para que possam entender o que os autores estavam fazendo. Ele deu a entender que a pesquisa rigorosa pode permitir que os historiadores construam um corpo de conhecimento factual através do qual se estabelece o que um autor pretendia fazer: "se obtemos sucesso em identificar esse contexto com precisão, podemos finalmente ter a esperança de compreender o que um orador ou escritor no qual estamos interessados estava fazendo (SKINNER 1988, p. 275). Para Skinner, o contextualismo permitiu aos historiadores evitar o anacronismo e alcançar interpretações válidas. As interpretações anacrônicas apresentam autores como participantes de debates que, conforme demonstrado pelo contexto, não estavam em voga quando os autores escreveram. As interpretações válidas recuperam as intenções dos autores de tratar de questões particulares em momentos particulares. Skinner apresentou seu método contextualista como a única maneira de evitar mitos anacrônicos (SKINNER 1988, p. 29-67).

Enquanto os historiadores modernos tentaram superar a distância histórica através do uso de métodos rigorosos, os pós-modernos a adotaram. Frank Ankersmit e Hayden White insistiram que historiadores e narrativas sempre remanescem separados do passado e dos fatos (ANKERSMIT 1983; 1994; 2001; WHITE $1973 ; 1978 ; 1987)$. Eles enfatizaram que os historiadores constroem suas representações e narrativas não somente para encaixar os fatos mas também 
através de metáforas, enredo e outras estratégias textuais. Ankersmit e White, no entanto, demarcaram uma abordagem distinta para a teoria histórica. Eles se afastaram tanto dos princípios especulativos dos historiadores desenvolvimentistas quanto da metodologia dos historiadores modernos. Eles focaram nas estruturas literárias e nas escolhas estéticas envolvidas na escrita histórica.

Ankersmit e White estão associados a uma abordagem "pós-moderna" da teoria histórica. Seu pós-modernismo aparece nas implicações aparentemente relativistas de sua ênfase na distância entre fatos e narrativas e também na sua preocupação com questões estéticas e literárias. Ironicamente, no entanto, embora Ankersmit e White sejam descritos como pós-modernos, sua abordagem sobre a teoria histórica ecoa o modernismo e implicitamente rejeita o pós-fundacionismo. Ankersmit e White se baseiam em uma compreensão da distância histórica como uma disjunção entre, por um lado, fatos e descrições, e, por outro, narrativas e representações. Eles expressam uma visão moderna de fatos atomizados. Às vezes, chegam a sugerir que os fatos são dados como verdadeiro ou falso dependendo se eles correspondem ou não ao mundo. Ankersmit por muito tempo tem sugerido que frases mínimas descritivas podem ser verdadeiras ou falsas em um sentido correspondente e tem explicitamente defendido experiências pré-cognitivas fora da linguagem e da teoria (ANKERSMIT 2005). White há muito tem destacado os eventos como itens cronológicos dados pelo enredo que os historiadores impuseram a estes eventos e tem explicitamente defendido que a realidade dos eventos no passado é independente de seu retrato literário (WHITE 1999).

Os pós-modernos diferem dos modernos não por sua compreensão da distância histórica, mas por sua resposta a ela. Os modernos tentaram superar a distância histórica apelando para métodos rigorosos para assegurar fatos e narrativas. Os pós-modernos festejaram a distância histórica, argumentado que ela é constituinte da escrita histórica enquanto uma forma de empenho literário, ao invés de se tratar de objetivar exclusivamente verdades fatuais. Em sua visão, a escrita histórica era distinta dos escritos científicos factuais precisamente porque a distância histórica significava que os historiadores inevitavelmente utilizam recursos literários e modos estéticos de representações.

\section{O pós-fundacionismo: uma solução contemporânea}

A distância histórica não é necessariamente um problema. Não foi um problema para muitos historicistas desenvolvimentistas que utilizaram princípios teleológicos e materiais para garantir a continuidade histórica e fundir fato e narrativa. A distância histórica se tornou um problema apenas quando os modernos rejeitaram tais problemas, abrindo-se à possibilidade de divisões entre passado e presente, fatos e narrativas. Os modernos queriam que a teoria histórica se concentrasse nas epistemologias e metodologias cujas lacunas os historiadores poderiam preencher. Os pós-modernos não apenas não descartaram o problema da distância histórica como acabaram por adotar sua causa. Argumentado que a lacuna entre o passado e o presente e entre fato e narrativa nunca poderia ser superada, redefiniram a teoria histórica como 
o estudo das dimensões estéticas e literárias que eram intrínsecas à escrita histórica por causa dessa inevitável lacuna.

Os pós-fundacionistas rejeitaram o modernismo de uma forma que dissipa a questão da distância histórica. Antes que eu explore o pós-fundacionismo, porém, preciso resolver uma possível confusão na terminologia. O pósmodernismo é, às vezes, definido como sinônimo de - ou pelo menos um subconjunto do - pós-fundacionismo. ${ }^{3}$ No entanto, os teóricos históricos pósmodernos não parecem ser pós-fundacionistas. Ankersmit e White podem rejeitar a ideia de que as narrativas históricas possam ser declaradas como falsas ou verdadeiras simplesmente por apelarem a fatos. Mas eles não parecem rejeitar a ideia dos fatos puros fora das categorias e da linguagem. Pelo contrário, eles definem as narrativas históricas em contraste a esses fatos, sugerindo que tais fatos existem, mas que a escrita histórica não é fixada por eles. Por exemplo, White recorre à "transição do nível do fato ou evento no discurso ao nível da narrativa"; ele argumenta, "esta transição é efetuada pelo deslocamento dos fatos no fundamento das figurações literárias ou, o que equivale à mesma coisa, pela projeção destes fatos na estrutura do enredo de um ou outro dos gêneros da figuração literária (WHITE 1987, p. 47). Assim, na teoria histórica, os pósmodernos podem contestar a possibilidade de as narrativas serem fixadas pelos fatos, mas eles não contestam, como fariam os pós-fundacionistas, a possibilidade de assegurar os fatos.

Deixe-me voltar ao pós-fundacionismo e às suas implicações para a 18 distância histórica. Os pós-fundacionistas acreditam que nenhum conhecimento é absolutamente certo. Frequentemente, eles acreditam mais especificamente que o conhecimento nunca possui fundações seguras na experiência pura ou na razão pura. Os pós-fundacionistas têm várias razões para rejeitar a certeza. Alguns enfatizam o conteúdo instável dos signos e a importância das relações entre os signos (DERRIDA 1976). Outros enfatizam a impossibilidade de atribuir significado ou a condição de verdade para proposições isoladas fora de uma rede maior de crenças. Por alguma razão, os pós-fundacionistas concordam que não existe experiência pura. As experiências são necessariamente carregadas de teoria. São em parte constituídas por categorias, tradições, discursos e linguagens precedentes.

Para compreender totalmente as implicações do pós-fundacionismo para a distância histórica, precisamos entender como isso altera as noções de fato e de objetividade (QUINE; ULLIAN 1970). O pós-fundacionismo acaba com a certeza dos fatos, se esses fatos derivam diretamente da experiência pura ou indiretamente por métodos rigorosos. A aceitação de uma experiência particular ou de um método necessariamente depende de teorias precedentes que são falíveis. Para os pós-fundacionistas, um fato não é dado, é uma prova que quase todo mundo de uma dada comunidade aceita, talvez até mesmo tenha uma boa garantia de aceitação devido a outras crenças intersubjetivas daquela comunidade. A definição de um fato decorre do reconhecimento da natureza

\footnotetext{
3 Para uma visão mais historicamente flexível do pós-modernismo, ver (BEVIR; HARGIS; RUSHING 2007).
} 
carregada de teoria da experiência. Como a teoria necessariamente entra na experiência, não podemos descrever um fato ou uma declaração de como as coisas são. Fatos sempre envolvem categorias prévias. Eles não são verdades certeiras. São coisas que atualmente concordamos em aceitar como verdade em função de outras coisas em que acreditamos (BEVIR 1999, p. 31-77).

Uma análise pós-fundacionista dos fatos sugere que eles são sempre entrelaçados com as narrativas. Um fato adquire seu caráter como um resultado de sua relação com outros fatos. Uma narrativa não apenas explica os fatos postulando relações de significado entre eles, mas também revela o caráter desses fatos. Novamente, as narrativas não apenas revelam o caráter dos fatos, elas criam seu caráter e guiam nossas decisões sobre o que conta como um fato. Como não há observações puras, os historiadores parcialmente constroem o caráter de um fato através de suas narrativas.

O pós-fundacionismo mina a possibilidade de tratar fatos como seguros fora de teorias e narrativas. No entanto, insistir na natureza carregada de teoria dos fatos não é necessariamente adotar o relativismo. Os pós-fundacionistas podem redefinir a objetividade em termos de uma comparação sensata entre as narrativas disponíveis. Nesta perspectiva, o conhecimento objetivo depende dos historiadores na crítica e na comparação de narrativas em relação aos fatos em questão. Os historiadores não podem dizer que uma narrativa é comprovada ou falsificada pelos fatos, porém podem comparar as narrativas em termos de seu relativo sucesso em relacionar os fatos a outros entre si destacando suas similaridades, diferenças e conexões. Às vezes, pode ser que não exista uma maneira de os historiadores decidirem entre duas ou mais narrativas, mas este será sempre o caso e, mesmo que o seja, os historiadores ainda poderão decidir entre essas duas ou mais narrativas e muitas outras de qualidade inferior.

Um conceito de conhecimento objetivo como um produto de uma comparação entre histórias rivais levanta a questão de qual critério deve guiar a comparação. Minha opinião é que nós poderíamos derivar tal critério do pressuposto do pósfundacionismo. ${ }^{4}$ Como a questão de definir o critério de comparação surge especificamente para os pós-fundacionistas, nós podemos razoavelmente presumir uma perspectiva pós-fundacionista ao responder à questão. O próprio pós-fundacionismo pode, assim, gerar critérios tais como a precisão para os fatos em questão, a cobertura completa dos fatos relevantes, a consistência e a compatibilidade com os padrões de evidência em questão, e uma progressiva, frutífera e aberta relação a outras narrativas. Por enquanto, no entanto, o ponto importante é que seja qual for o critério que os pós-fundacionistas adotem, eles irão conceber a objetividade como o resultado de uma prática de comparação ao invés de um confronto entre a narrativa e os fatos evidentes.

A análise pós-fundacional dos fatos e da objetividade dispensa o problema da distância histórica. Em termos gerais, o pós-fundacionismo mina a ideia de que 
fatos sobre o passado são dados fora das teorias e narrativas do presente; funde passado e presente, fatos e narrativas. Considere-se, mais especificamente, a preocupação moderna com a distância histórica. Uma que vez que os modernos desistiram dos princípios dos historicistas desenvolvimentistas, eles tentaram justificar as narrativas recorrendo aos fatos atomizados. A separação de fatos e narrativas parecia crucial se os fatos serviam para justificar as narrativas. O problema para os historiadores modernos era então superar a distância histórica, evitar anacronismo e certificar os fatos. Sua solução eram os métodos rigorosos. No entanto, os pós-fundacionistas negam a possibilidade de separar os fatos das narrativas como também o passado do presente. O conteúdo dos fatos necessariamente reflete as narrativas nas quais eles estão localizados. Não pode haver fatos fora de narrativas. Não pode haver acesso ao passado fora de nossa reconstrução atual dele. Os modernos poderiam se preocupar que abrir mão da possibilidade de fatos certificados fora das narrativas deixa os pós-fundacionistas sem saída para justificar o conhecimento histórico. Os pós-fundacionistas responderão que esta preocupação erroneamente presume que a justificativa requer um tipo de certidão que simplesmente não podemos ter. Eles dirão que o conhecimento histórico é objetivo não por virtude de sua correspondência a determinados fatos, mas por virtude de ser a melhor descrição atualmente disponível.

Agora considere a abordagem pós-moderna à distância histórica. Os pós-fundacionistas podem parecer alinhados aos pós-modernos na 20 rejeição à possibilidade de justificar as narrativas pela referência aos fatos certificados. No entanto, os pós-fundacionistas diferem significativamente do pós-modernismo de Ankersmit e White. Os pós-modernos aceitam uma explicação moderna da distância histórica. Eles aceitam a separação dos fatos e das narrativas como também do passado e do presente. É que justamente os pós-modernos argumentam que não há como superar essa separação; as narrativas históricas necessariamente envolvem tropos literários que as distinguem dos registros cronológicos de eventos. No entanto, os pós-fundacionistas rejeitam a possibilidade de fatos fora de contextos teóricos. Todo conhecimento incorpora tanto fatos quanto teorias. Até mesmo as cronologias dos eventos são inerentemente carregadas de teoria. Desse modo, o pós-fundacionismo enfraquece a ênfase pós-moderna na suposta tropologia peculiar das narrativas históricas. Todo conhecimento - incluindo a ciência natural como também a história - envolve um tipo de construção teórica ou literária dos fatos (BEVIR 1999, p. 31-77). O pós-fundacionismo, assim sendo, faz o caminho de uma narrativa que envolve um tipo de projeção irrelevante para sua validade. Isso torna a questão relevante sobre a razoabilidade da forma de projeção que a narrativa envolve. Ao dissolver a distância histórica, o pós-fundacionismo remove os fundamentos sobre os quais os pós-modernos tentaram redefinir a teoria histórica como o estudo da natureza peculiarmente literária e da natureza estética das narrativas e representações históricas. 


\section{Repensando a teoria histórica}

Como o pós-fundacionismo dissolve a distância histórica, ele contesta as duas principais abordagens teóricas do século $X X$ da teoria histórica. Em princípio, o pós-fundacionismo contesta a teoria moderna com seu foco em fatos e suas ambições metodológicas. A teoria histórica não precisa ser sobre elaborar rigorosos métodos para certificar os fatos. Nenhum método pode certificar os fatos independentemente de um conjunto falível e contestável de teorias contextuais. O conhecimento objetivo depende não de métodos e fatos, mas de um processo de comparação. Além disso, o pós-fundacionismo contesta a teoria pós-moderna com seu foco no estudo das características literárias e estéticas da escrita histórica. A teoria histórica não precisa mais ser sobre tropologia e sim sobre a filosofia da ciência. Sem dúvidas, a apresentação de todos os tipos de conhecimento pode envolver recursos literários; mas as formas na quais as narrativas históricas vão além dos fatos e incorporam teorias não as distingue de nenhum outro tipo de conhecimento.

O pós-fundacionismo aponta para uma nova abordagem da teoria histórica - menos metodológica, menos literária e mais filosófica. A teoria histórica pode perguntar questões epistemológicas sobre o conhecimento e a crença. $\mathrm{O}$ que é o conhecimento da história? Como os historiadores deveriam justificar suas crenças sobre o passado? A teoria histórica pode perguntar questões ontológicas sobre objetos que historiadores postulam quando descrevem o passado: que tipos de objetos compõem o passado? Os historiadores devem conceber variados objetos em termos estabelecidos pelo realismo, nominalismo ou construtivismo? E a teoria histórica pode perguntar questões metafísicas sobre conceitos relevantes para a explicação histórica, incluindo causa e efeito, vontade e determinismo, tempo e identidade: os seres humanos são capazes de ações inovadoras? Que formas de explicação os historiadores devem adotar para explicar crenças, ações e práticas?

Uma abordagem pós-fundacionista para a teoria histórica seria diferente do modernismo e do pós-modernismo. Diferente do pós-modernismo, ela não se concentraria em histórias escritas para explorar sua construção literária. Ao invés, retornaria às questões filosóficas sobre as formas de justificação e explicação que historiadores deveriam adotar. No entanto, ao contrário do historicismo moderno, ela não diria aos historiadores como realizar suas pesquisas - quais métodos a adotar ou a renunciar. Em vez disso, exploraria a gramática de nossos conceitos na tentativa de livrar os historiadores dos efeitos sedutores do modernismo.

Meu argumento sobre a distância histórica exemplifica essa abordagem pósfundacional da teoria histórica. Ela subtrai as implicações conceituais do pósfundacionismo na tentativa de libertar os historiadores de qualquer preocupação insistente e moderna sobre a relação do passado com o presente ou do fato e com a narração. Ela não eliminou a distinção entre passado e presente apenas se preocupa com essa distinção. De fato, ainda que o pós-fundacionismo nos permita descartar as preocupações sobre a distância histórica, ela não apaga a distinção entre o passado e o presente. O pós-fundacionismo garante 
sobreposições e continuidades entre passado e presente ao localizar o passado em nossas redes de crenças do presente, mas mantém uma distinção em nossas redes de crenças entre o passado e o presente. Novamente, para situar o ponto de uma outra maneira: o pós-fundacionismo distingue o passado e o presente, mas como o historicismo desenvolvimentista, ele nos fornece uma consonância histórica. O pós-fundacionismo nega a ideia que existiria um abismo intransponível entre o passado e o presente, entre o fato e a narrativa. Como o historicismo desenvolvimentista estabeleceu uma ponte do presente de volta ao passado por meio de princípios, então o pós-fundacionismo o faz localizando ambos em uma única rede de crenças. ${ }^{5}$ Para os pós-fundacionistas, a possibilidade de o passado ser totalmente estranho ao presente nem sequer é levantada, o passado é apenas o passado do modo como o compreendemos no presente.

Os críticos podem sugerir que os pós-fundacionistas ainda enfrentam preocupações parecidas com aquelas relacionadas à distância histórica; os pós-fundacionistas ainda podem se preocupar com a adequação do uso dos conceitos do presente para transmitir conceitos bastante diferentes do que eles atribuem às pessoas no passado. No entanto, essa crítica falha em reconhecer a extensão em que o pós-fundacionismo diminui as preocupações sobre a distância histórica, reformulando-as como questões de tradução ou de re-descrição dentro da nossa própria rede de crenças. A dificuldade não é mais chegar do presente ao passado; é apenas descrever o que acreditamos sobre o passado e, às vezes, pelo menos transmitir nossas crenças sobre o passado aos outros utilizando conceitos aos quais

22 são compreensivelmente familiares. O pós-fundacionismo dissolve o problema da distância histórica em um conjunto de crenças e conceitos mais abrangente e ainda mais manejável para descrever e comunicar.

Para ver como o pós-fundacionismo reformula preocupações dramáticas em problemas comuns acerca da distância histórica sobre re-descrição, vamos olhar brevemente para três questões específicas. A primeira questão é o relativismo conceitual ou a legitimidade do nosso tratamento de nossas ideias como válidas para outros tempos e lugares. A segunda questão é o significado textual ou a legitimidade de atribuir às ações significados que elas não poderiam ter tido na época. A última questão é a re-encenação ou a legitimidade de utilizar nossos conceitos para cobrir ideias muito diferentes do passado.

\section{O relativismo conceitual}

Os relativistas conceituais questionam a legitimidade do tratamento de nossos conceitos como válidos para outras épocas. A posição deles parece implausível, obviamente com o respeito ao conhecimento do mundo natural. Certamente, se os historiadores discutissem a erupção do Monte Vesúvio, eles poderiam utilizar nosso conhecimento do comportamento vulcânico ainda que

\footnotetext{
${ }^{5}$ A diferença entre as visões pós-fundacionista e pós-moderna do conhecimento foi um dos principais temas em meu debate com Ankersmit. Ankersmit argumentou que o conhecimento histórico nos obriga a "fazer" conceitos enquanto o conhecimento cotidiano nos exige a "corresponder" nossos conceitos a algo de fora deles. Eu respondi que todo o conhecimento envolve "fazer" - nós nunca podemos "corresponder" os conceitos a determinados. Ver: (BEVIR; ANKERSMIT 2000, p. 351-372).
} 
esse conhecimento não tenha sido compartilhado pelas pessoas em Pompéia na época da erupção. Os historiadores podem utilizar livremente nosso conhecimento atual sobre o comportamento vulcânico porque esse conhecimento, na nossa visão, é sobre leis universais.

O relativismo conceitual aparece mais problemático quando os historiadores discutem a vida humana. Se historiadores descrevem ou explicam o passado utilizando conceitos de ação e significado, eles infligem violência às pessoas que não professaram aqueles conceitos? Se as pessoas não se concebem como sujeitos agindo por próprias razões, os historiadores podem legitimamente discutir suas ações em tais termos? Os historiadores podem aplicar nosso conceito de ação sobre outros, desde que nossa análise desse conceito sugira que ele se aplica universalmente. No entanto, a ideia relevante da aplicabilidade universal não pode ser fornecida por nenhuma quantidade de evidência empírica. (A evidência empírica não pode dar suporte a tal universalidade em parte por causa do problema familiar da indução e em parte porque a evidência empírica incorporaria a análise a qual ela deveria dar apoio, de modo que a justificativa da análise por sua referência à evidência seria tautológica.) Se os historiadores querem dar aplicabilidade universal para o nosso conceito de ação, então eles devem fazê-lo por meio de argumentos filosóficos. Os historiadores têm que demonstrar que a gramática dos nossos conceitos é tal que nosso conceito de ação se aplica a outros tempos. Novamente, os historiadores se desviam do relativismo conceitual mostrando que intencionalidade e o arbítrio são características invariantes do nosso conceito de ação.

Um relativista conceitual poderia reclamar que nossa análise conceitual da ação, com sua relação à noção de intencionalidade, pode ser falsa. Mas essa queixa não é o ponto. A questão não é defender nossos conceitos como Verdade em qualquer sentido metafísico amplo. É simplesmente para mostrar que nossa crença nesses conceitos nos compromete com algumas posições. Uma vez que concordamos que não possuímos prova conclusiva sobre a Verdade de nossos conceitos - um ponto ao qual os relativistas dão bastante peso - o fato de que nossas crenças podem não ser a Verdade deve nos preocupar muito pouco. O que nos irá preocupar é, primeiro, que nossos conceitos são aqueles que utilizamos por boas razões e, segundo, que esses conceitos implicam a razoabilidade da aplicação de nossa análise conceitual da ação sempre que discutimos as ações.

\section{O significado textual}

Os apelos filosóficos à gramática dos nossos conceitos permitem aos historiadores defender o uso de conceitos abstratos referentes às capacidades humanas universais. É difícil imaginar tais argumentos filosóficos aplicados a conceitos concretos que determinam o conteúdo a essas capacidades. A gramática dos nossos conceitos pode justificar um historiador tratar as pessoas como agentes mesmo que elas não tenham se compreendido como tais, mas isso não parece justificar nenhuma alegação de que os agentes atuam universalmente de uma determinada maneira. Novamente, pode não ser anacrônico discutir se pessoas tiveram a capacidade para o arbítrio se elas não possuíram tal conceito, mas 
talvez é anacrônico discutir o arbítrio de Shakespeare como expressado em Júlio César ${ }^{6}$ de uma forma que atribui a ele nossa concepção de relógio de punho.

A distância histórica muitas vezes é discutida em relação à legitimidade de atribuir às ações significados que elas poderiam ter tido naquele tempo (SKINNER 1988). ${ }^{7}$ Como a noção de Polis de Aristóteles difere de nosso conceito de Estado, talvez seja anacrônico referir ao seu texto como se fosse um tratado sobre o Estado. Apenas são legítimas as leituras que evocam as intenções dos atores? Quase todas as tentativas de resolver esta questão caem na falácia do significado textual. ${ }^{8}$ Elas procedem como se os textos tivessem significados intrínsecos, sejam esses significados singulares ou plurais. Muito há a ganhar insistindo que os significados são sempre significados para as pessoas. Um texto só é um movimento físico, tinta no papel, ou óleo sobre a tela. Um texto ganha significado somente se um ou mais indivíduos atribuem significado a ele. A gramática de nossos conceitos nos impede de postular significados que não podemos atribuir a pessoas específicas.

Embora os textos somente tenham significados para as pessoas, essas pessoas não precisam ser autores dos textos. Eles podem ser leitores, inclusive nós mesmos. Sendo assim, os historiadores podem legitimamente atribuir a textos significados que os seus autores, mesmo seus autores contemporâneos, podem não ter tido a intenção de produzir. Os historiadores apenas têm de ser claros para quem o texto teve esses significados. Os historiadores poderiam dizer que o texto de Aristóteles significou algo para os leitores no século XIX, ou que significa algo para nós, e eles podem fazê-lo mesmo se aquele significado

24 não é o qual Aristóteles ou seus contemporâneos poderiam plausivelmente ter atribuído ao texto.

\section{Re-encenação}

Talvez os problemas da distância histórica surjam não porque os historiadores aplicam nossos conceitos ao passado, mas porque eles atribuem às pessoas crenças que essas pessoas poderiam não ter considerado. Contudo, não temos fundamentação filosófica para descartar a possibilidade de alguém ter tido uma crença. Temos apenas bases empíricas para considerá-la como altamente improvável que eles assim fizeram. Propriamente falando, portanto, as falácias anacrônicas ocorrem quando atribuímos às pessoas crenças que empiricamente acreditamos ser extraordinariamente improvável que elas tenham tido. A distância histórica aparece quando os historiadores utilizam nossos conceitos para se referir a conceitos muito distintos que eles atribuem às pessoas no passado.

A análise da distância histórica permanece complexa mesmo depois de reduzi-la a tentativas de re-encenar as crenças passadas. As complexidades

\footnotetext{
${ }^{6}$ Nota dos tradutores: Tragédia que contém um famoso exemplo de anacronismo. Em seu ato primeiro, cena segunda, um diálogo faz referência a um relógio mecânico que ainda não havia sido inventado no tempo em que a peça era datada, 44 a. C., mas que era presente nos tempos de seu autor, Shakespeare.

7 Embora Skinner se apresente como discutindo interpretações textuais anacrônicas, penso que ele erra seu alvo e que sua real preocupação é com as re-encenações anacrônicas.

8 Outro assunto em meu debate com Ankersmit foi a validade de equacionar os significados com a intencionalidade dos indivíduos. Ver: BEVIR; ANKERSMIT, 2000.
} 
vêm à tona quando nos lembramos de que as crenças passadas não são objetos aos quais os historiadores têm acesso direto. Elas são objeto que os historiadores postulam com base em evidências. Ainda mais complexidades vêm à tona quando percebemos que o processo de postular crenças inevitavelmente cria uma lacuna entre essas crenças e as palavras em que elas são expressas. Ainda que os historiadores possam ter somente o registro das palavras que Aristóteles utilizou em sua Política, o resultado seria uma transcrição. Quando os historiadores postulam crenças, eles selecionam as palavras para isso. A esse respeito, a re-encenação é mais bem descrita como atribuição.

Portanto, podemos diferenciar entre a atribuição de crenças anacrônicas e o uso de palavras anacrônicas para evocar crenças. Somente a primeira é um problema. Os erros anacrônicos surgem quando um historiador atribui a pessoas crenças sobre coisas que não existiram no tempo em que elas viveram. Mas mesmo esses erros são às vezes apenas casos nos quais os historiadores não estão suficientemente esclarecidos sobre o nível de abstração em que estão descrevendo as crenças relevantes. Por exemplo, se os historiadores escrevem sobre a visão de Aristóteles acerca da separação de poderes, um crítico pode objetar que Aristóteles poderia não ter tido crenças sobre a separação de poderes. Se historiadores estão utilizando a frase "separação de poder" em um sentido estrito para se referir aos poderes Executivo e Judiciário do governo como sendo institucionalmente distintos do Legislativo, o crítico sem dúvida poderia ter um excelente ponto. No entanto, se os historiadores estão utilizando a frase em um sentido mais abstrato para teorias constitucionais nas quais nenhum órgão tem a palavra final sobre decisões coletivas, parece muito menos certo que Aristóteles não possuía as crenças necessárias para considerar tais assuntos. A questão aqui não é a re-encenação através da distância histórica, mas a adequação de conceitos abstratos para casos mais particulares dadas certas circunstâncias.

\section{Conclusão}

Espero ter dissipado o problema da distância histórica. Como fiz esse truque? Meu argumento geral foi que as preocupações sobre a distância histórica surgiram apenas quando os historicistas modernos quiseram certificar suas narrativas recorrendo a fatos atomizados e a métodos rigorosos. Os modernos se preocuparam que a distância dos fatos pudesse minar a verdade de uma narrativa. Em nítido contraste, argumentei que o pós-fundacionismo mina a ideia dos fatos puros não apenas na teoria histórica, mas para todo o conhecimento. Ele coloca um problema geral de como definir o conhecimento objetivo sem apelar a fatos puros. Eu sugeri que nós o fazemos ao conceber o conhecimento objetivo como um produto de uma comparação entre as descrições rivais disponíveis. Este conceito de objetividade remove a necessidade por fatos puros. Isso nos permite dispensar as preocupações sobre a distância histórica como um efeito sedutor da ideia moderna dos fatos atomizados.

O pós-fundacionismo, assim, derruba a explicação comum da distância histórica e do anacronismo. A distância histórica é concebida em termos da relação entre objetos passados e contextos presentes. O anacronismo 
tipicamente aparece como um posicionamento de um objeto em um contexto inapropriado. O aparecimento de um relógio de punho em uma peça sobre a antiga Roma é um caso paradigmático. No entanto, o pós-fundacionismo sugere que nós não temos objetos e contextos com o grau de fixidez pressuposto por essa análise do anacronismo. Assim, transformei a distância histórica em uma relação entre nossos conceitos e as crenças que atribuímos às pessoas no passado. Quando pensamos sobre a distância histórica dessa maneira, três questões se destacam. Primeiramente, precisamos esclarecer o alcance conceitual dos nossos conceitos. Discuti aqui que podemos refutar o relativismo conceitual utilizando argumentos filosóficos sobre a gramática de nossos conceitos. É aparentemente clara a falta de universalidade de nosso conceito de um relógio de punho, o qual faria sua aparição em Júlio César, responsável pela acusação de anacronismo pernicioso. Segundo, precisamos perguntar a quem pertencem as crenças que queremos narrar. Argumentei aqui que nós legitimamente podemos atribuir a ações significados que elas não tiveram na época, desde que estejamos certos que os significados relevantes existiram para leitores posteriores. O autor de Júlio César poderia defender a aparição de um relógio de punho na peça dizendo que sua produção dizia respeito ao significado que a peça tinha para ele enquanto uma história sobre o poder absoluto. Finalmente, precisamos perguntar o quão precisamente nossos conceitos capturam as crenças que queremos narrar. Argumentei aqui que o grau requerido de precisão varia com o propósito e o nível de abstração

26 da narrativa. Um autor pode argumentar que sua obra procurou tratar das questões de poder em um nível suficientemente abstrato para traduzir, em nossos termos, em que Shakespeare acreditou.

\section{Referências bibliográficas}

ADCOCK, R; BEVIR, M; STIMSON, S (orgs.). Modern Political Science: angloamerican exchanges since 1880. Princeton: Princeton University Press, 2007.

ANKERSMIT, F. Historical Representation. Stanford: Stanford University Press, 2001.

History and Tropology: the Rise and Fall of Metaphor. Berkeley: University of California Press, 1994.

Narrative Logic: a Semantic Analysis of the Historian's Language. Den Haag: Nijhoff, 1983.

Sublime Historical Experience. Stanford: Stanford University Press, 2005.

BENTLEY, M. Modernizing England's Past: English Historiography in the Age of Modernism 1870-1970. Cambridge: Cambridge University Press, 2005.

BEVIR, M. Sidney Webb: Utilitarianism, Positivism, and Social Democracy. Journal of Modern History, v. 74, p. 217-52, 2002. 
. The Logic of the History of Ideas. Cambridge: Cambridge University Press, 1999.

; ANKERSMIT, F. Exchanging Ideas. Rethinking History, v. 4, p. 351372, 2000.

; HARGIS, J.; RUSHING, S. (orgs.). Histories of Postmodernism. New York: Routledge, 2007.

BURROW, J. A Liberal Descent: Victorian Historians and the English Past. Cambridge: Cambridge University Press, 1981.

Evolution and Society. Cambridge: Cambridge University Press 1966.

CAPALDI, N. John Stuart Mill: a biography. Cambridge: Cambridge University Press, 2004.

DERRIDA, J. Of Grammatology. Trans. G. Spivak. Baltimore: Johns Hopkins University Press, 1976.

KLOPPENBERG, J. Uncertain Victory: Social Democracy and Progressivism in European and American Thought, 1870-1920. New York: Oxford University Press, 1986.

LASLETT, P. (orgs.). John Locke's Two Treatises of Government: A Critical Edition with an Introduction and Apparatus. Cambridge: Cambridge University Press, 1960.

. "Introduction". In: LASLETT, P. (ed.). Philosophy, Politics and Society. Oxford: Basil Blackwell, 1956.

NOVICK, P. That Noble Dream: the "Objectivity Question" and the American Historical Profession. Cambridge: Cambridge University Press, 1988.

OTTER, S. den. British Idealism and Social Explanation. Oxford: Clarendon Press, 1996.

QUINE, W.; ULLIAN, J. The Web of Belief. New York: Random House, 1970.

ROSS, D. "On the Misunderstanding of Ranke and the Origins of the Historical Profession in America". In: IGGERS, G; POWELL, J (orgs.). Leopold von Ranke and the Shaping of the Historical Discipline. Syracuse: Syracuse University Press, 1990, p. 154-169.

. The Origins of American Social Science. Cambridge: Cambridge University Press, 1991.

SKINNER, Q. "A Reply to Critics". In: TULLY, J. (org.) Meaning and Context: Quentin Skinner and His Critics. Cambridge: Polity Press, 1988. . Interview by Petri Koikkalainen and Sami Syrämäki. Finnish Yearbook of Political Thought 6, 2002.

. "Meaning and Understanding in the History of Ideas". In: TULLY, J. (org.) Meaning and Context: Quentin Skinner and His Critics. Cambridge: Polity Press, 1988. 
WHITE, H. Figural Realism: studies in the Mimesis Effect. Baltimore: Johns Hopkins University Press, 1999.

Metahistory: the Historical Imagination. Baltimore: Johns Hopkins University Press, 1973.

The Content of the Form. Baltimore: Johns Hopkins University Press, 1987.

. Tropics of Discourse. Baltimore: Johns Hopkins University Press, 1978.

28 